purchaser. The purchaser in the NHS is increasingly going to demand evidence of the outcomes of medical care in contracts, and not just details of the process.

This book is a collection of essays arising from a conference on this issue. As with any such book, it has its high spots and its depths. An introduction by the chief medical officer was interesting, but contains a statement that there is wide variation in mortality in young male diabetics in England above a table which clearly shows the opposite. Parts on orthopaedic outcomes left me cold, but a section on death rates as a comparator of performance were very interesting, as were chapters on cost effectiveness, and the development and implementation of clinical guidelines. While outcomes in a well-defined area such as total hip surgery should be relatively easily measured, I was left wondering how to monitor outcomes in my own general medical practice, with its broad case mix. This book does not provide the answer, but may stimulate some thought.

T WALLEY

Department of Pharmacology and

Therapeutics,

University of Liverpool, Liverpool L69 3BX, UK

\section{Health care policy}

Controversies in health care policies challenges to practice, $M$ Marinker, ed. pp 128. BMJ, London, 1994. $£ 12.95$, paperback

This book arose from a series of six workshops addressing issues which rarely hit the front pages of the press but are part of the infrastructure underlying many of the big debates. The editor, a well known academic general practitioner and iconoclast, personally selected the dozen or so participants in each, on the basis of their expertise in the relevant areas and acted as moderator in each. The chapters were then written by one of the participants from each workshop. The editor writes an excellent introductory chapter, discussing the nature of uncertainty in medical practice and the value of clinical judgement, the conflicts and paradoxes that exist at all levels of medical management, and the weakness of the process by which we reach consensus on what we should do. This chapter alone makes the book worth reading, as it is an excellent exploration of the state of medical professionalism in the 1990s.

Other highly commendable chapters cover the nature of risk in medical practice, the effects of an aging population on the health service and vice versa, and the nature of the prescribing decision in general practice (and why prescribing may always be partly illogical to anyone except the prescriber). There were some disappointing chapters too: on information on health (at several levels) in an open society, on the effects of medical practice variations, and on how to evaluate recent reforms. Perhaps my choice of these as less than satisfactory reflects my clinician's bias, but somehow I felt that these were written for a manager who didn't actually know much about the NHS. So on the whole, this book is worth reading for doctors, managers and others interested in where the health service is today, and where it might go in the future.

Department of Pharmacology and Therapeutics, University of Liverpool, Liverpool L69 3BX, UK

\section{Medical algorithms}

Acute medicine algorithms, $M$ Singer, AR Webb. pp vii +172 , illustrated. Oxford University Press, Oxford, 1994. paperback

Algorithms are not devices which generally appeal to the medical reader on this side of the Atlantic as much as they seem to do in North America; this may reflect the less technocratic, more pensive approach that has until recently characterised the British approach to clinical practice. This splended little textbook is therefore all the more interesting because it seems to represent the first in a new generation of textbooks destined to fill white coat pockets in Accident and Emergency Departments up and down the UK. The book is assured of a runaway success. The reasons are plain: succinct decision-making pathways through every important or common medical emergency are simple to follow and are accompanied by pithy discussion of the key issues associated with human crises. The $\mathbf{7 0}$ or so sections - from basic resuscitation to anaphylactoid reaction - are laid out in an orderly and sensible fashion; redundant verbiage is avoided by a judicious blend of linked algorithms and a delineation of salient points in plain English. There is plenty of blank space for making notes and the whole is embellished with a well-chosen selection of truly contemporary references. This publication has certainly changed my prejudices against algorithms; a number of colleagues have already enthused about it and I have little doubt that Singer and Webb have pro- duced one of the medical classic of the 1990s and beyond.

Department of Accident and Emergency

Medicine,

Royal Liverpool University Hospital, Liverpool L7 8XP, UK

\section{What is in a hospital name?}

Hospital names: a history of British hospital names, $M$ Smith, A Sakula. pp 108. Royal Society of Medicine Press, London, 1994. $£ 10$. ISBN 1-85315-241-2.

Are you the type of postgraduate who is curious about the names of hospitals or wards or the portraits which often adorn entrances to hospitals? You may be a little apprehensive that in an interview for a hospital appointment somebody will ask you why it is called the Adelina Patti Hospital, Swansea, or the Chaucer Hospital, Canterbury, or the George Eliot Hospital, Nunaton, or the Cromwell Clinic, Huntingdon. It is just possible that in the MRCP clinical some rogue examiner will ask why it is named Whittington Hospital, Highgate, or Addenbrooke's Hospital, Cambridge, or Radcliffe Infirmary, Oxford

The Nelson Hospital, Merton, commemorates, of course, Admiral Viscount Horatio Nelson (1758-1805) because he lived in Merton until he left for the Battle of Trafalgar. The wards, now occupied by geriatric patients, have names associated with Nelson's battles, his ships and his captains, and the signal 'Every man shall do his duty' is flow from the hospital mast on Trafalgar Day, 21 October. A bust of Nelson stood on a pedestal at the front of the building until it was stolen in 1979.

Stanley Hospital, St Asaph, is named after Welshman HM Stanley, born John Rowlands in nearby Denbigh. In 1867 he joined the New York Herald newspaper and was sent on many overseas expeditions. In 1869 he was given the laconic instruction 'find Livingstone'; and this he did.

There is a delightful new little book on the names of $\mathbf{4 0 0 0}$ or so British hospitals. The names fall into six groups - famous people, perhaps a local dignitary; doctors and nurses of renown such as Addenbrooke, Maudsley, and Florence Nightingale; royalty and aristocracy; benefactors and saints.

It only costs $£ 10$ so it will surely become a popular filler of Christmas stockings.

DG JAMES

Royal Free Hospital School of Medicine, London NW3 $2 P F, U K$ 